\title{
The Issue of Urban Transport Planning in Saudi Arabia: Concepts and Future Challenges
}

\author{
Khalid Mohammed Almatar*, Abdulaziz I. Almulhim
}

Department of Urban and Regional Planning, College of Architecture and Planning, Imam Abdulrahman Bin Faisal University, P.O. Box 1982, Dammam 31451, Saudi Arabia

Corresponding Author Email: kmalmatar@iau.edu.sa

https://doi.org/10.18280/ijsdp.160712

Received: 3 September 2021

Accepted: 16 November 2021

\section{Keywords:}

transport planning, Saudi Arabia, social impact assessment, metropolitan transportation plan

\begin{abstract}
Sustainable mobility is a growing field that allows researchers to pay attention to the problem of public transit and its constraints. In spite of this, many developing countries often overlook this aspect of the question and focus on monetary issues instead. This causes an imbalance between a variety of sources of impact, such as the local economy, environmental problems, and even social interactions. The case of Riyadh, one of the essential transports and financial arteries of Saudi Arabia, was important because it showed that the city administration is yet to invest more resources in the existing Metropolitan Transportation Plan (MTP) and improve other non-quantifiable factors. The method applied for this research was a detailed review of the current plan that was completed in an attempt to highlight the biggest weaknesses and identify the opportunities to capitalize the future local transport planning. It was proposed to implement the Social Impact Assessment (SIA) method and formulate clearer objectives regarding how metro and bus stations should be located and maintained in order to make it easier for the citizens of Riyadh to reach all necessary destinations. A renewed framework is proposed to help the city administration cope with the increasing agglomeration and unemployment rates.
\end{abstract}

\section{INTRODUCTION}

People are accustomed to mobility, since they engage in economic or social activities that require them to travel from one place to another. According to Dalvi [1], an exceptional level of mobility brings more capabilities related to career opportunities, housing, and employment. Therefore, the infrastructure where mobility is one of the central elements has to include investments and enough space for all the necessary externalities. For example, an urban area has to be set up rather carefully due to the existence of interrelations between components revolving around the technological and organizational aspects of transport systems [2]. Transport planning remains one of the most complex tasks that require a meticulous understanding of inherent transportation issues. Since the pressure on transportation infrastructure keeps increasing with demand and economic growth, the sustainability and consistency issues need to be addressed.

Transportation planning revolves around the ability of the administration to exploit available resources while striving for adequate change and maintenance. According to the findings of Diao [3], additional investments could be necessary to unfold and maximize the potential of the given location while also considering human needs and interests. In a sense, transport sustainability cannot be achieved in an environment devoid of social justice, environmental solutions, and economic strength. Transport sustainability is, therefore, a concept that requires transport managers to consider a variety of components, including environmental and social factors, when deciding how the infrastructure should be set up [4]. The popularization of the concept of sustainability can be perceived as a high-paced trend that requires city administrations to pay more attention to social concerns rather than investing resources on initiatives that do not have public support [5]. It is vital to review the social impact of sustainable transportation since it plays an integral role in community life and opens up a range of possibilities for innovation and positive outcomes.

The inherent social dynamics that affects the concept of transportation planning should be included in the traditional quantitative evaluation of the initiative [6]. It would be a crucial step for large cities looking to enhance their metropolitan areas and create efficient and logistically helpful transport networks [6]. Developing countries are often exposed to problems related to the social impacts of urban transport because of their sporadic growth and the inability to invest more resources in transportation initiatives [7]. The lack of an adequate transport infrastructure places Saudi Arabia among the countries where travel conditions are evolving [8]. The biggest problem that needs to be resolved is the growing rate of social exclusion, which undermines the accessibility of public transport and reflects the need for Riyadh administration to focus on the social impacts and dimensions of transport planning [9]. As mentioned above, the pressure is growing continually, making the gap between supply and demand wider, especially in the transportation sector [10]. The social context of transport infrastructure may require improvement to draw attention to the problem and create a more positive outlook on transportation planning in general.

The discussion of urban transportation planning in Saudi Arabia, particularly in Riyadh, is vital in order to assess the government's willingness to align its operations with Vision 
2030. The main objective included in the plan is to promote self-financed projects and private participation in the development of transport infrastructure (e.g., roads, ports, railroads, and airports) [11]. A strong focus on partnerships with private organizations will allow Saudi Arabia to set up new public-private enterprises and gain advantage in supply chain management. Even though full privatization is not very likely to occur, the private sector cannot be ignored or limited in terms of its involvement in the transport infrastructure. This paper will help readers gain more insight into the main transportation issues affecting Saudi Arabia and the city of Riyadh in particular. As transportation planning initiatives are not sufficiently developed yet, the current project aims to conduct a detailed analysis of Riyadh's transportation network to determine how different iterations of the social context of transportation could affect the planning process. A significant reason for the relevance of this study is that Riyadh currently experiences transportation issues, and this research project could provide some insight into potential solutions. The main contribution of this study would be to emphasize the importance of sustainability in transportation and underline the need for a detailed transportation plan for Riyadh. As for the novelty of the study, the researchers propose to review the metropolitan transportation plan for Riyadh by means of social impact assessment methodology. This study will enhance the social element of transportation planning by identifying the impactful concepts related to the transport infrastructure of the city.

\section{SOCIAL CONTEXT OF TRANSPORTATION AND TRANSPORT ASSESSMENT PRACTICES}

\subsection{Literature on the subject of social elements of transportation}

Until the 2010s, the social context of transportation had not been extensively addressed in literature because there was no clear definition of the social impact. There were no researchers who went beyond the concept of mobility to redefine social transportation in the light of concepts such as wellbeing and social exclusion [12]. The social element of transportation may be defined as the existence of either positive or negative impacts on transport sources due to the perception or preferences of end-users (civilians, social categories, or groups of individuals) [13]. According to this definition, transportation planning must consider the current action framework, not just as a quantitative instrument but as a tool that includes both behavioral and psychological elements, which contribute to mobility of commuters. Therefore, it may be an essential task for scholars and government officials to examine the factors that influence transport planning.

The first crucial element of urban transport planning that must be addressed in Riyadh is to provide greater accessibility, which would attract more commuters to the given transport system. In a study it was noted that people should be able to reach their destinations with minimum limitations or delays, regardless of the direction of their travel [14]. It is evident from the available literature that the notion of accessibility includes the end-user, the transport system, travel time, and land use [15]. Nevertheless, the issue is even more complex because accessibility may depend on additional factors such as leisure activities, housing, wellbeing, and available health services [16]. Peterson argues that end-user characteristics such as gender, income, and vehicle ownership can influence the accessibility of transportation systems significantly and therefore, they must be considered when it comes to analyzing the overall transportation systems [17].

The urban environment recurrently affects the design and usability of transport plans due to the level of accessibility, socio-economic opportunities of local citizens, and land use mix [18]. Therefore, unique lifestyles, travel choices, and interpersonal interactions may impact the mental and physical health of service solicitors [19]. In order to mitigate health risks, it is necessary to engage more parties and individuals in transportation planning since it would be difficult to address the limitations associated with neighborhood disadvantages and socioeconomic status over time [20]. For instance, a cardependent area would have poorer environmental quality, which is likely to deteriorate physical health of individuals more. A car-free transportation plan may become a viable option in those areas where individuals are willing to abandon their cars to reduce road fatalities and increase road safety. The provision of proper transportation infrastructure can alleviate various inequities and contribute to a more sustainable city.

Another problem associated with transportation infrastructure is the inherent rate of crime which needs to be addressed effectively. Individual perceptions of safety revolve around certain socio-economic characteristics and cannot be ignored when it comes to public transportation or transport planning [21]. According to the existing evidences, women experience more anxiety than men in public transport facilities [22]. So, it may be worthwhile to provide transport stations with sufficient security measures like CCTV cameras and adequate lighting so that commuters would feel confident and safe. It is important to note that disadvantaged groups should be included in discussions to know how crime can affect their travel behavior [23]. It is an important area that must be discussed with people who may be socially segregated based on certain characteristics. For instance, abused children, mentally handicapped individuals, single parents, and other specific populations could be perceived as misfits due to their inconsistency with common social outlooks [24].

The issue of exclusion and inclusion implies that people are distinguished based on their legal equality, cultural capital, sociability, education, professional skills, among others. This factor not only reflects a democratic outlook of the problem of transportation, but it also redefines how it may be perceived by the citizens themselves [25]. The inherent multidimensionality of this issue makes some of the individuals or groups of people reluctant to social participation, resource acquisition, and proper socialization [26]. On a larger scale, even one's political and cultural aspirations may affect the transportation planning process. Inclusion and exclusion are directly correlated with one's quality of life and contribution to society. For instance, if people are secluded, it puts them at a significant disadvantage because they do not have the opportunity to realize their potential; and poverty being one of the problems affecting the deprived individuals [27]. The key social aspects of seclusion and inclusion are as follows: accessibility of social services, availability of employment opportunities, and possibilities of social involvement. Consequently, the problem with seclusion is that there may be opportunities available to individuals; however, they may not be able to access them and take their advantage [28]. Accordingly, transportation-related seclusion revolves around one's ability to travel and access all the necessary locations when needed [29]. 
Another crucial aspect when discussing transportation planning in relation to social seclusion is the impact of personal wellbeing on mobility choices and opportunities [30]. If the community exerts sufficient effort to establish a positive influence on the local mobility strategies, its members would most likely limit the occurrence of seclusion and find ways to improve the existing state of affairs [31]. City administrations tend to overlook personal wellbeing when planning internal mobility and transportation due to a lack of evidence on the topic. When evaluating the segregation process and its impact on future transportation perspectives, one cannot ignore the prospect of increased quality of life [32]. The prevailing interconnections between mobility and wellbeing have to be placed under the hood of transportation planning since social relationships influence the process of decision-making.

Structural equation modeling can help determine how to improve mobility and determine how people can reduce the rate of seclusion without limiting their movements [33]. It is important not to minimize transportation options' disadvantages because most policymakers view the dynamics of transport planning as an unavoidable issue that needs to be accepted [34]. Nevertheless, it may be considerably safer to predict areas where seclusion would be the strongest and implement policies that increase mobility instead of hindering them. The development of transportation initiatives that link psychological wellbeing to available transport options is needed to create combinations that address unemployment, traffic congestion, and other potential policy goals [35].

The notion of impartiality plays a crucial role in municipal transport planning because it defines the available benefits and potential costs of providing all members of society with equal opportunities. In order to distinguish between distribution and distribution-related processes, three factors must be considered: all possible benefits that are available to the distribution party, the groups of individuals that are eligible for receiving the intended benefits, and the presence of the principle of impartiality that can prevent the administration from making improper decisions [36]. For transportation planning initiatives, the administration must ensure that distribution-related decisions are fair in order to extend commuters' reach and create the optimal price-quality ratio. The problem that needs to be solved is the lack of adequate public funding in cases where public funds can help strengthen impartiality and help different disadvantaged groups gain access to benefits [37].

\section{SOCIAL CONTEXT OF TRANSPORT PLANNING ASSESSMENT IN RIYADH}

In terms of transport planning initiatives, one essential concern that demands resolution is bringing transportation analysis from strictly engineering to a context that includes psychological and social science conditions.

\subsection{Evaluation of social magnitude in terms of transport planning}

The emphasis on sustainability and accessibility raises the possibility that classic transport plans may not function as expected anymore, creating a need for a more suitable means of delivering appraisal methods. As a result, this serves as one of the key predictors of scenarios in which decision-making tools need to consider people-centric approaches and weigh the social consequences of transport policies [38]. Traditional frameworks are no longer as efficient as they were described several decades ago. This is why the influence of the Social Impact Assessment (SIA) has to be considered when looking into social impacts and their inherent impact on the regulatory context of transport planning [39]. Moreover, traditional frameworks are no longer as effective as they were described several decades ago, therefore considering the influence of Social Impact Assessment (SIA) should be considered when looking at social impacts and how they affect the regulatory context of transport planning [39]. Presently, the SIA provides a detailed framework for assessing certain social issues that arise when planned interventions are deployed into production. One of the main advantages of this method is that every stage of the project's life cycle may serve as a platform for assessing the initiative. Consequently, both direct and indirect effects of social impact issues can be considered allowing for a sustainable environment that is both ecologically and economically boosted.

In the case of planned intervention, the idea is to implement SIA practices to identify the magnitude of the effects caused by decisions made by stakeholders. Additionally, there is a chance to identify pivotal alternatives that do not adversely affect the financial and technical state of the decision-making body [40]. The presence of such compensation mechanisms highlights the benefits of SIA and outlines it as a mitigation measure even for the most complex cases of transport planning. In addition, SIA offers stakeholders much more opportunity for engagement since there may be numerous marginalized groups looking to introduce changes to how the community is affected by the available transportation options. As stakeholders discover potential, they might be interested in aligning their interests and resources with the community's needs and considering social impacts [41]. As a result, the team will have the opportunity to predict several outcomes of projected choices and dwell on the most equitable solutions. Furthermore, SIA can be changed to have infinite follow-up assessments designed to improve the state of affairs.

An increasingly high level of responsiveness can be achieved with the help of SIA, allowing stakeholders to foresee most of the unanticipated influences of transport planning and dynamically address them upon recognition. Considering the importance of urban transport planning, it may be safe to say that the biggest advantage of SIA to date is the possibility of adapting projects to any specific environment since exceptional scalability is in place [42]. An even bigger advantage is the ability to tailor the solution to any planning level and environment. When utilizing SIA, a variety of stakeholders may be interested in establishing stronger cooperation and following up every planning stage in an attempt to improve existing operations. From the local scale, the administration could move up to the national level of planning and emphasize the difference between social impact and social goals of transport planning. The main reason for the distinction is the inclusion of positive social targets into the plan, with the presence of certain factors not predicting any kind of change, either positive or negative [43]. In other words, simply recognizing social impacts is not enough when it comes to urban transport planning since numerous planning activities rely on the accommodation of community concerns.

Accordingly, when SIA is applied to transport planning, it provides stakeholders with an opportunity to evaluate equity outcomes and gain more insight into the core distributional effects, such as seclusion, for example. Therefore, the social magnitude of transport planning and respective decision- 
making can be mitigated by a cooperative strategy where the community actively contributes to developing and deploying solutions intended to improve the quality of life and wellbeingrelated outcomes [44]. Some of the possible transport policies that could affect Riyadh on a long-term scale revolve around multi-stakeholder approaches, community transformation, transport policies, and city-shaping decisions. There will be positive outcomes from any new project designed to increase social participation in Riyadh because it will bypass the daily routines of stakeholders to improve the lives of citizens. From safe traveling patterns to amended logistics, the administration is going to see numerous benefits allowing for agile transport planning and proper social impact management.

\subsection{Current practices in MENA and Europe}

The evaluation of national appraisal practices, which can reduce the cost of transport, is essential within modern projects designed to develop new approaches to transportation planning. The weaknesses of multi-criteria analysis and costbenefit analysis as assessment methods were addressed in literature as crucial delimitations averting the administration from considering non-monetized society's impact on transport planning. Therefore, the SIA practice has to be utilized more often in order to provide the MENA region with more advantages related to transport planning. A multi-criteria analysis may also be needed to establish the basis of a qualitative assessment and to help city administration pay attention to equity, air pollution, social cohesion, climate change, and other aspects of transportation planning that cannot be quantified also stated that the assessment framework would often lack equity due to the complexity of the appraisal that should involve indirect socio-economic variables [45].

Across the MENA region, the Enable - Avoid - Shift Improve (EASI) framework is used to set up urban transport planning and redefine how local city administrations attain sustainability in their operations [46]. The Enable section encourages the creation of an environment that allows for the development of new mobility transition plans based on existing capacities, stakeholders' interests and available resources, and active regulatory structures. Public participation may also be required in order for city administrations to set a positive example [47]. The Avoid segment of the framework is expected to reduce the number of trips made by end-users. In other words, the MENA region expects to manage transport demand more efficiently through land-use planning and stronger transport infrastructure [48]. The Shift element of the framework is going to pave the way for more environment-friendly solutions and eventually develop a completely new strategic direction for the majority of developing countries from the region [49]. At a certain point, public transport may be expected to become more appealing for the MENA end-users. The Improve segment of the plan focuses on reducing emissions and improving traffic management [50]. Knowing that the current transport demand is peaking in the MENA region, governments have to invest in system and technology improvements in order to survive.

\section{SOCIAL IMPACT OF TRANSPORTATION POLICIES IN RIYADH CITY}

\subsection{Adopted methodology}

The current project represents a detailed exploration of how social seclusion could be aligned against mobility in Riyadh. The authors dwell on how social isolation could be addressed by the local administration by means of a proper introduction of a transport planning policy. The aim of the current project is to investigate Riyadh transportation and see how the influence of the social context of transportation affects the planning process. Riyadh, as one of the essential transport and economic arteries of Saudi Arabia, has to be examined in terms of how it may cope with social issues and their influence on transport planning across the different stages of the latter. In order to complete this analysis, the author considered the transportation plan of Riyadh while complementing the research with a thorough geospatial analysis. The two research questions the author intended to answer at the end of the project were as follows:

- Are the objectives of Riyadh's Metropolitan Transportation Plan evocative enough to be considered relevant? Are there any social impacts and dimensions included in the discussion throughout the documentation?

- Does the existing Metropolitan Transportation Plan possess all the elements of a guide that considers the social impacts of transportation? How can Riyadh address the existing gaps in Metropolitan Transportation Plan development?

The following content analysis was required to gain additional insight into the crucial weaknesses of current EIA practices and deploy several recommendations for improving the framework. The method of content analysis was utilized to highlight essential data regarding transport planning and evaluate the basics of the EIA framework. The case of Riyadh assisted the researcher in terms of outlining the most beneficial and destructive practices while also relating all the evidence to the Metropolitan Transportation Plan of Riyadh. This was necessary because access to the planned transport system could not be evaluated in-depth, leaving the city administration struggling with the extraction of relevant evidence. The initial stage of the research was to assess the objectives included in the document and see how they aligned against the goals of local citizens and the social impacts of transport planning. The second step revolved around picking evidence regarding equity, seclusion, wellbeing, and accessibility in an attempt to establish a qualitative foundation for further verdicts. The ultimate stage of the research project was to assess the strength of social impacts inside transport planning and evaluate the progress made by Riyadh over the course of the last five years. The researcher was able to determine if the social goals of transportation planning are based on an accurate perception of social issues that are experienced by citizens in addition to decision-making events for the city administration.

\subsection{Urban transport crisis in Riyadh}

Ever since the foundation of the City of Riyadh, the administration has exerted considerable efforts to provide its citizens with adequate alternatives for personal cars. The need to reduce dependency on automobiles prompted the administration to reduce funding for road infrastructure development [51]. In addition to the common issue of traffic congestion, Riyadh citizens also have to cope with the cultural and social influences of transport planning. Due to the initial model of public transport planning being brief and lacking 
detail, the administration of Riyadh had to cope with the increasing competition established by privately operated minibuses that deteriorated the process of urban planning and caused transportation chaos on a larger scale.

A competitive disadvantage developed over time, where more citizens of Riyadh became dependent on commuter transit and personal vehicles in order to commute to work [18, 52]. In Figure 1, a densely populated city center can be seen as the core of most activities. The respective inefficiency of transport and transit services plays a significant role because personal transportation options (e.g., cars) became the primary choice for Riyadh citizens. Ultimately this caused a significant level of traffic congestion and forced the local administration to elaborate Metropolitan Development Strategies that would consider urban expansion and its social impacts [53].

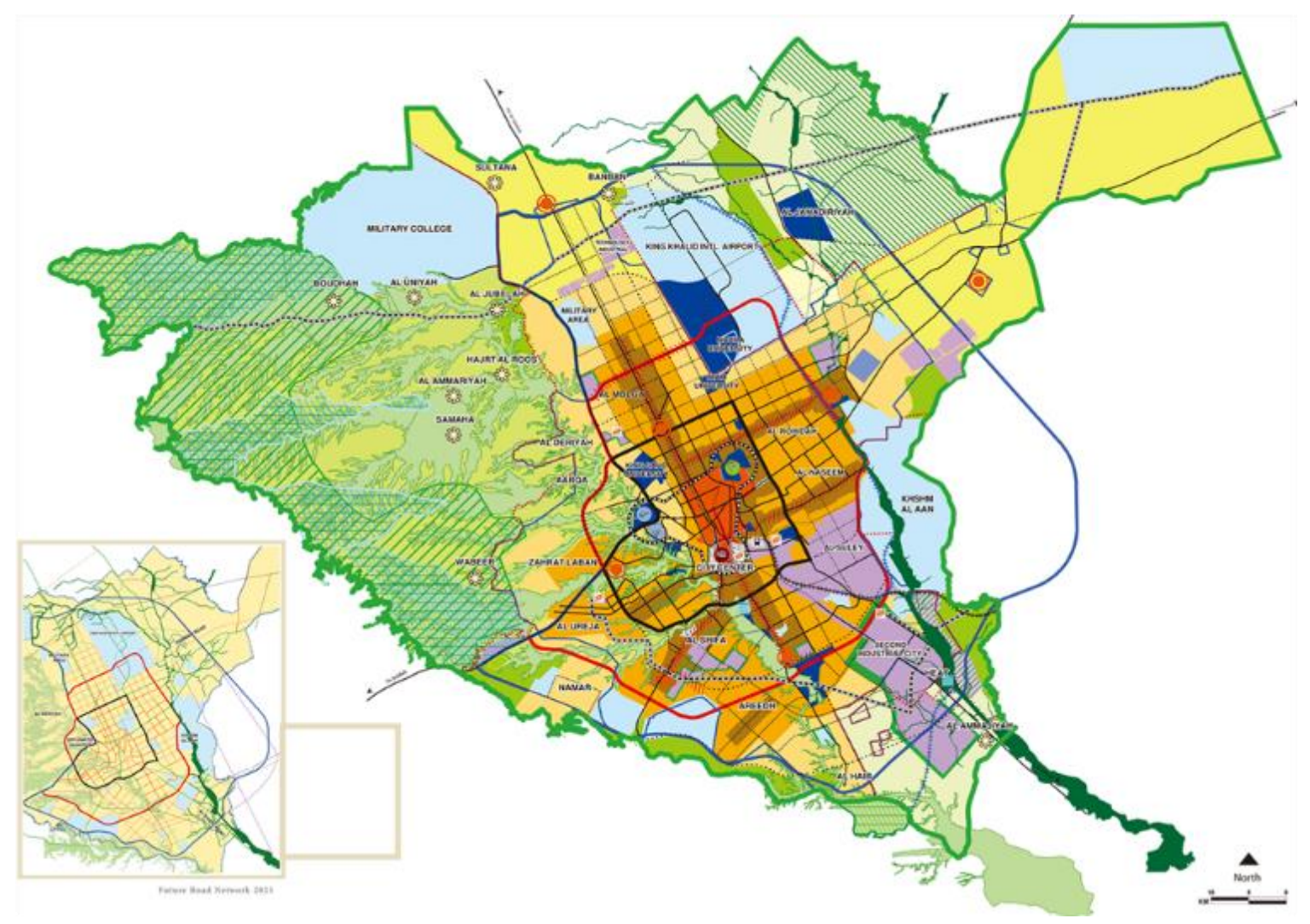

Figure 1. The city of Riyadh: A map of population density and area distribution

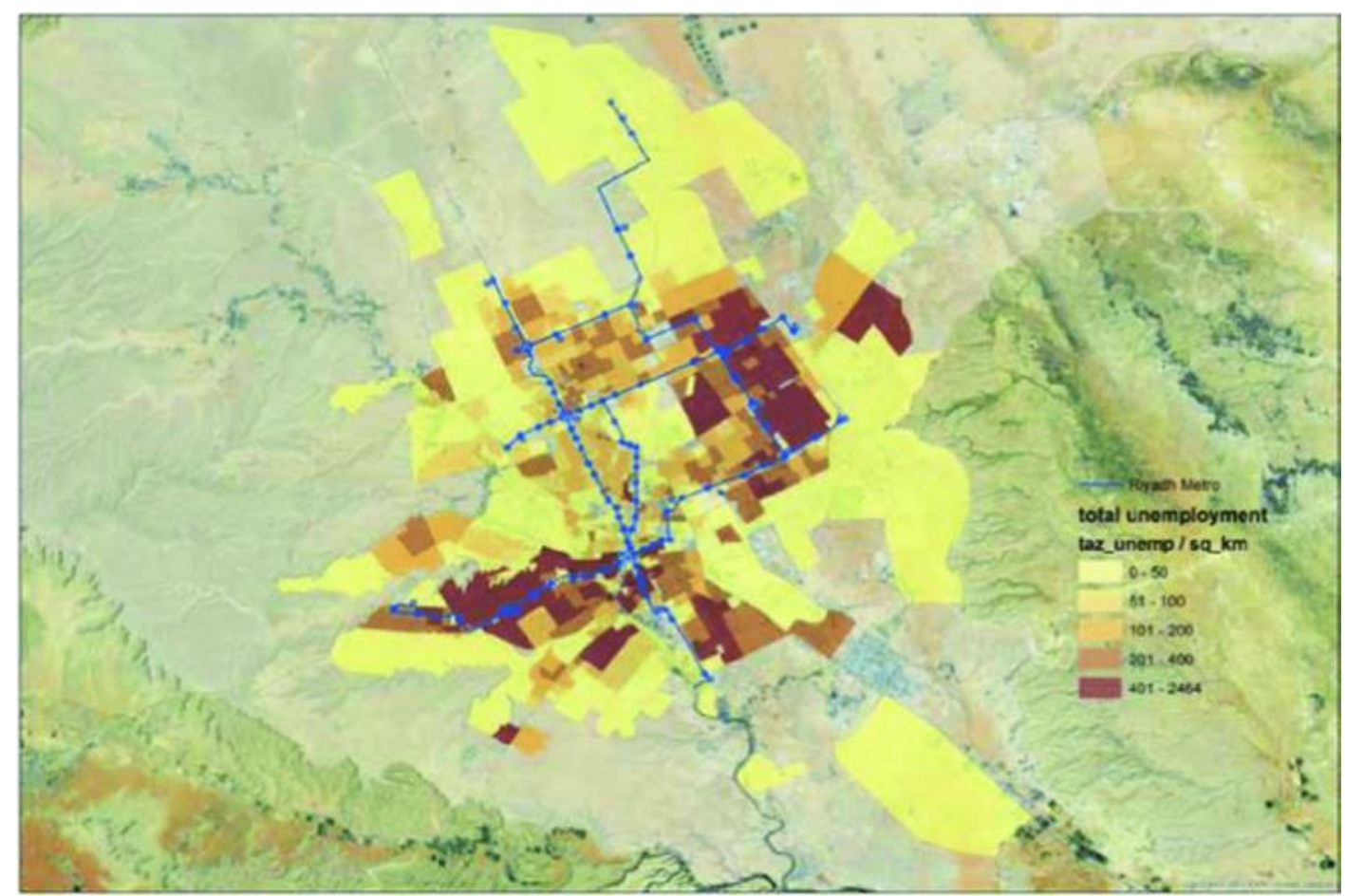

Figure 2. The city of Riyadh: A map of unemployment. Retrieved from Almaatouq [54] 
Figure 2 shows a few lower-income segments that cause scattering in service and industrial zones. The rapid expansion of Riyadh caused numerous individuals to rely on their means of transport due to the lack of urban mobility established by the transport administration, especially in the downtown area. With the amount of pressure on Riyadh steadily increasing, the administration must assess all the challenges and opportunities in order to prevent hindering the participation and economic opportunities of civilians expecting to make the best use of public buses and metro stations. Overall, the current mobility crisis in Riyadh can be seen as the result of the administration not having the capability to upgrade existing routes and prioritize in-depth assessment of qualitative variables. Based on the above evidence, it may be argued that the fundamental priority for the Riyadh city administration should be to acknowledge the existence of an urban mobility crisis and exert efforts aimed at the upgrade of routes and public access to transport. Further smart growth is going to aid the city in terms of economic development and enhanced decisionmaking that is going to cover public needs of the disadvantaged as well. Since there are several disadvantaged areas, the administration could also try to increase the efficiency of its transport planning initiatives, since only joint effort can be expected to help stakeholders increase public transport coverage.

\section{INTRODUCING THE SOCIAL CONTEXT IN THE PROBLEM OF TRANSPORT PLANNING IN RIYADH}

\subsection{The role of urban planning}

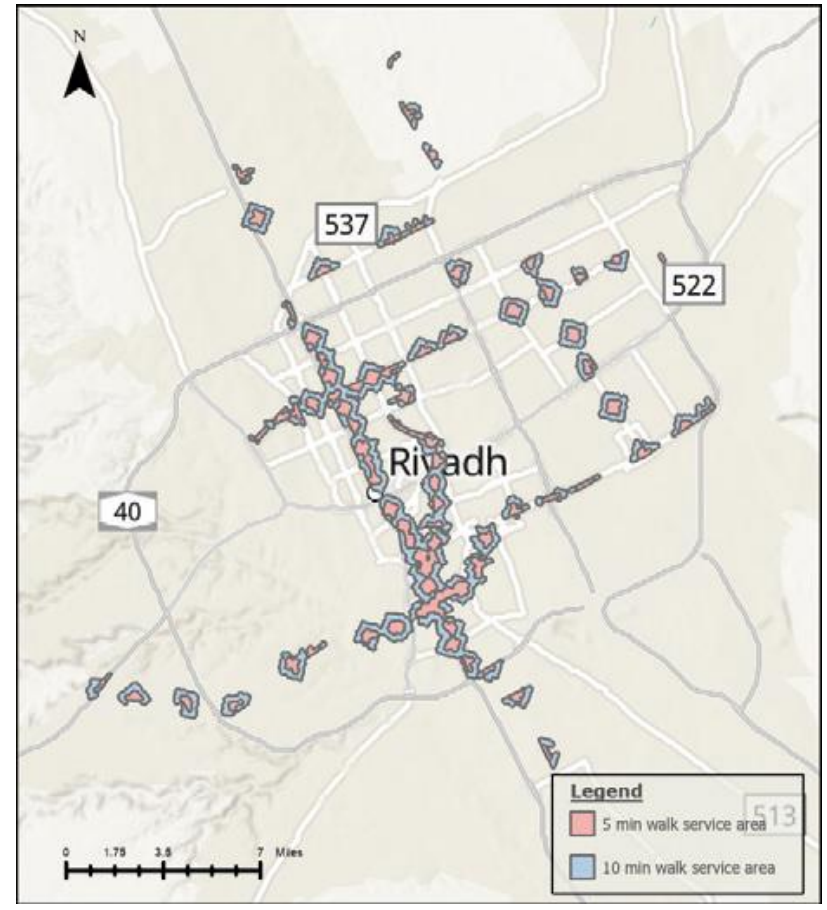

Figure 3. The city of Riyadh: A map of service areas around metro stations available via 5-10 minute walks. Retrieved from reference [55]

One of the challenges that have always affected transport planning in modern Riyadh was the ever-increasing pace of urban development. Not only did it cause problems in the area of urban sprawl, but it also affected the accessibility of different job locations situated in the metropolitan area (see
Figures $3 \& 4$ ). The majority of previous transport plans failed to address the need to control urban areas and overcome insufficiencies through the interface of long-term planning [24]. The main aim of the Riyadh administration may be to establish a new framework for the development of the transportation sector that took economic and social aspects into account before making any decisions. This new course of action could help the city administration cope with the increasing traffic congestion and motivate individuals to give up their personal means of transport in order to utilize the metro or public buses [56]. This innovative approach to public transportation accessibility may prove crucial when helping to map land-use planning and centralized guidelines included in the new transport plan. The growth of agglomeration defines the future of the metropolitan Riyadh area since the infrastructure has to be extended reasonably in order to address most of the transport-related shortcomings that are accompanied by a quickly decreasing rate of unemployment [57]. The inherent ambitions of the updated plan have to remain in line with population mobility needs and additional requirements that may be established by individuals using personal cars to get to destinations.

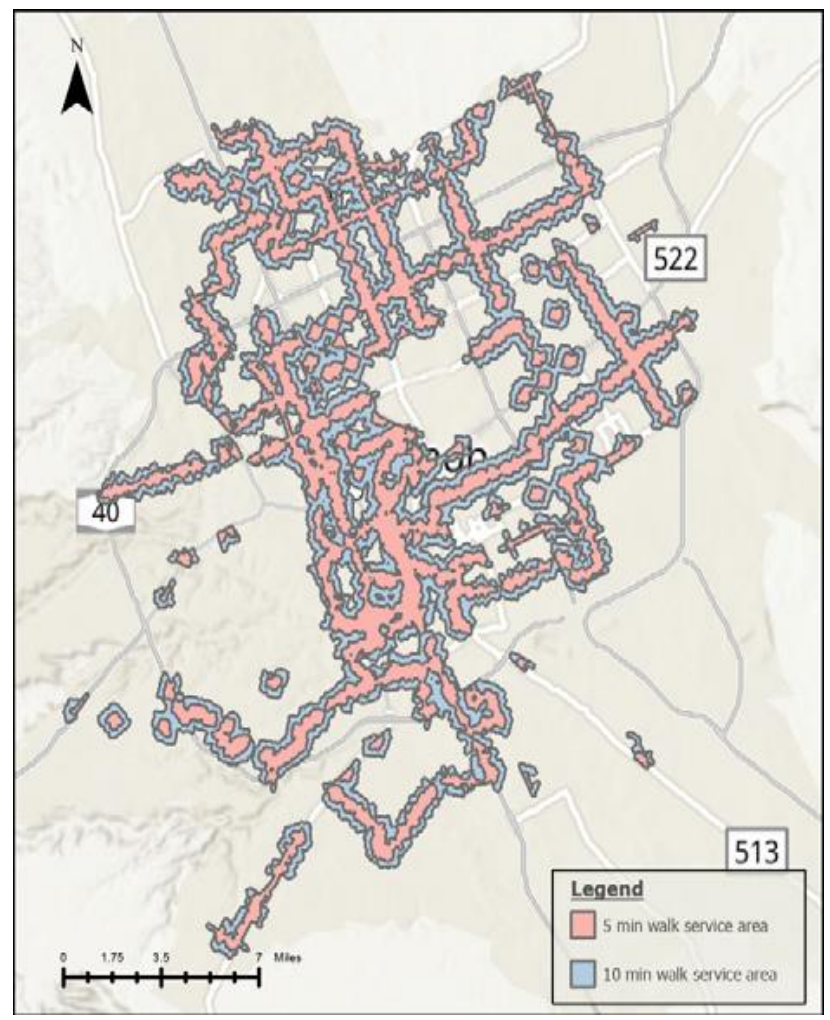

Figure 4. The city of Riyadh: A map of service areas around public bus stations available via 5-10 minute walks. Retrieved from reference [55]

\subsection{The metropolitan transportation plan for Riyadh}

Even with the barriers that prevent the city administration from deploying comprehensive responses to weak transport planning, it may be safe to say that the Metropolitan Transportation Plan could become one of the primary reasons for responsible stakeholders to embrace necessary initiatives. The gap between the current supply and the rate of population travel continues to increase, causing public transport organizations to struggle with providing the city of Riyadh with enough fleet and routes [58]. One of the best ways to 
outline crucial Metropolitan Transportation Plan and capitalize on them would be to establish the probable course of development for the MTP and its derivatives. Every action must be operationalized and ready for deployment before it can prove successful and provide the administration with a competitive advantage.

\subsection{The metropolitan transportation plan -- course of action}

The city administration's first task would be to form a technical committee that could be expanded by representation from public transport companies. From railway and metro to buses and taxis, Riyadh has to aim to facilitate the process of transportation through the interface of alternative strategies and decision-making that enhance mobility instead of hindering it [59]. For instance, the committee could focus on the following tasks while making sure that Riyadh benefits from the updated strategies:

- Deploying a new transport plan that is going to comprise multiple modules (e.g., metro, buses) in order to cover the perimeter of the metropolitan Riyadh;

- Establishing realistic solutions that could reduce the deficiency of local public transport and improve the feasibility of transport planning in Riyadh;

- Coping with traffic congestion and pollution in order to make sure the index of road safety is going to grow significantly, allowing the administration to minimize the influence of negative externalities [6062].

In addition to providing the citizens of Riyadh with adequate transportation options, the plan must remain a predictive instrument (see Figure 5). This figure illustrates how the existing transportation plan could be altered gradually to improve the quality and reliability of transport options. Nevertheless, the administration ought to gain a better understanding of how travel demand changes from year to year and if there are any potential ways to curb it [63]. To be able to accomplish this, the administration should allocate enough time and resources to do the following:

- Compile a list of the essential stakeholders that may affect the outcomes of the implementation of the new MTP;

- Scrutinize some of the most up-to-date transport planning documents in order to see how the agglomeration in the downtown Riyadh area could be reduced (from the perspective of projected land-use);

- Assess the state of affairs in relation to traffic on public roads and evaluate the quality of Riyadh infrastructure and its readiness for preventing roadrelated casualties;

- Revise the fare system to bring more people to public transport and motivate them to use personal vehicles for tourism and sightseeing purposes;

- Model the traffic demand and ensure that personal traveling behaviors are studied deeply enough to help the administration control the MTP in accordance with the needs of Riyadh citizens;

- Gain more insight into how the current road infrastructure holds up against the increasing transport demand and see how more public transport options could lead to positive outcomes;
- Evaluate the social costs of the new solution and see if it makes sense for the administration to overlook some of the crucial variables such as the greenhouse effect, different kinds of pollution, road casualties, and even traffic-generated noise [55, 64, 65].

Another element that cannot be ignored when it comes to data projections and a further diagnosis related to the MTP of the city of Riyadh is the traffic forecast that has to be dependent on the employment rate, social trends, and land-use profitability. The need for a more or less accurate estimate is required to see how the alternative strategies could affect transport planning across Riyadh and help citizens reach destinations quicker and more efficiently in terms of monetary expenditures and environmental impact [66]. The further completion of each of the steps is going to highlight every little milestone intended to transform the course of transport planning in Riyadh since the city administration will be able to complete the database with information on traffic problems and respective casualties. The extent of the new MTP for Riyadh cannot be translated into a solely numeric language because the existing infrastructure does not rely exclusively on statistics. In order to assess the future traffic needs of Riyadh, alternative scenarios need to be analyzed, along with estimating the social and economic costs of implementation.

1. Evaluating the existing situation

2. Forecasting possible advantages and limitations

3. Highlighting possible backup options for primary transportation solutions instruments named: cost-benefit analysis and multi-criteria analysis

4. Setting up planning procedures and developing adequate responses to the environment

5. Implementation of secondary projects and assessment of backup solutions

Figure 5. The metropolitan transportation plan process model for Riyadh

Saudi Arabia's growing car ownership is putting a strain on metropolitan infrastructure. Potential solutions could include adding tramways and revising the bus system to make existing routes more efficient [67]. It will be easier for citizens of Riyadh to reach their destinations without using personal transport if the administration comes up with more alternative strategies. The social cost of household cars continues to increase due to the negative environmental impacts of cars [68]. Accordingly, a cost-benefit analysis would most likely reveal the positive impact that can be achieved by adopting a revised MTP for public transport in Riyadh. Mobility is a comprehensive issue and there could be a host of additional factors that have not been considered in the literature thus far, meaning the Riyadh city administration does not have all the information it needs yet to make informed decisions and adopt secondary scenarios and supplementary measures. 


\subsection{Social context within the metropolitan transportation plan}

The idea that the new MTP would involve new evaluation methods may reinforce the importance of taking into account the social elements of transportation planning. Therefore, the key objective of the proposed strategy would be to reduce the negative environmental impact of existing transport options and create a highly safe road network, minimize noise pollution, and mediate pollution sources [69]. For the metropolitan area of Riyadh, traffic congestion caused by the increasing number of personal vehicles is a crucial issue to address. As a result of this trend, the city administration has difficulty addressing issues that go beyond statistics and numbers and revolve around accessibility and well-being [70]. There should be no ambiguity in the new MTP since transportation modes could affect the social context from several angles, such as traffic casualties, greenhouse effect prevalence, and various sources of pollution. There will be no opportunity for the city administration to resolve the traffic issue if it sees the problem in a mere monetary rapport.

It should be understood that seclusion and inclusion, equality, physical and mental health, and accessibility have been overlooked recurrently, causing problems inside the transport system. An exclusively number-based approach to the problem of transportation in Riyadh is unlikely to cause any positive outcomes since welfare is not the only variable to be considered in this case [71]. Therefore, it may also be necessary to develop new appraisal tools and approaches to cost-benefit analysis that are much more flexible and also consider the social element of transportation planning. As the cost-benefit analysis only looked at maintenance costs and required investments, the new MTP could also address road safety, comfort, and geographic accessibility in order to go beyond monetary measures [72]. These updates are going to be cumulative by nature, allowing the city administration to project the impact of the new transport planning policies and address each scenario from different points of view. Through the social context of the proposed MTP, the majority of budget constraints will be removed in favor of accessibility and affordability [73]. Without evident steps toward improved accessibility of public transport, the new MTP is not going to become a strong element of the transport infrastructure.

\section{RESULTS AND DISCUSSION}

The existing research findings reveal that Riyadh is currently grappling with policies centered around transportation and is considering social concerns as part of the discussion on a renewed MTP. It is inconceivable to disregard the social context as appraisal, implementation, and monitoring require the administration to look at all the trendsetting activities as potential room for innovation. However, no legal framework has been identified that permits Riyadh's updated transportation planning to be based on factors such as citizens' wellbeing, transportation accessibility, pollution levels, or any other variable that goes beyond simple monetary terms. The SIA could become the best instrument for the Riyadh city administration since it would provide strategies for protecting the environment and human resources. Another obstacle to implementing a new MTP is the lack of guidance across the administration that could facilitate decision-making and improve the structure of future transportation plans.

In addition, there is the issue of complying with international requirements released by funders that could influence the transportation planning process. Riyadh, for instance, could benefit from an updated transit system that would increase transportation safety and allow more people to reach their jobs faster with no delays. The inherent equity, in this case, would help portray transportation problem as an issue that goes beyond pollution and other social contexts because public risks cannot be dismissed. The city administration of Riyadh should pay more attention to the significance of public participation and keep in mind the benefits of attracting civilians to regulatory projects that are usually developed and deployed for the benefit of the locals. A detailed MTP would enable the deployment of a complex transport ecosystem that would also support decision-making and policymaking activities. The current project shows how the inclusion of social impacts in the discussion on the topic of transport planning would affect the whole infrastructure and leave clues for a more in-depth examination.

By looking at the given data, it may be safe to say that the overall accessibility of Riyadh's public transport is relatively low $[54,56]$. It poses a problem because many people may not want to commute long distances. Therefore, the lack of metros and bus stations forces locals to adapt to the existing conditions, leaving the Riyadh metropolitan area mostly deserted. Despite moving at a relatively high pace in terms of urbanization and infrastructural transformations, Riyadh does not seem to put enough effort into finding solutions that benefit both pedestrians and drivers. Instead, more highways are being constructed, replacing historical pedestrian layouts with a system that disregards ridership as a minor variable. To cope with the situation, the administration has to develop a new MTP and focus on walking accessibility since metro stations are way more accessible than public bus stations and bus rapid transit options.

\section{CONCLUSION AND RECOMMENDATIONS}

With the evidence collected within the current project, it can be concluded that social contexts are crucial when reviewing options for transportation planning and revisiting infrastructure. The key implication of the current study is that Riyadh's administration must address transport planning attributes more effectively regarding non-physical factors (e.g., pollution, noise, well-being). It is also important that the implications of the city's economic interests not overshadow the primary objective of obtaining a comprehensive social assessment framework and proper tools to address Riyadh's transportation concerns. Furthermore, Riyadh needs to consider how it can incorporate non-quantifiable risks into the discussion. This will be essential to foster a much more sustainable environment. The city administration may want to solicit more feedback from the community in a consistent manner to gain insight into what socio-economic trends are presently existent or possibly forthcoming in the region for better planning. The desocialization process is going to be averted with the help of in-depth SIA research and a thorough assessment of how the future MTP would benefit the most secluded populations across the city. From the very first step, project design units should focus on putting qualitative factors into perspective in order to help the community to get a better understanding of what they should expect from the upcoming 
transport planning initiative. The diversity of people's interests needs to be considered because it would also improve approaches to risk mitigation and advance the administration's policy-making capability. Further reliance on the SIA methodology is necessary if the city administration of Riyadh seeks valuable participation from the citizens and expects to gain international credit for an updated MTP.

\section{REFERENCES}

[1] Dalvi, M.Q. (2021). Behavioural modelling, accessibility, mobility and need: Concepts and measurement. In Behavioural Travel Modelling, 639-653. https://doi.org/10.4324/9781003156055-38

[2] Koszowski, C., Gerike, R., Hubrich, S., Götschi, T., Pohle, M., Wittwer, R. (2019). Active mobility: Bringing together transport planning, urban planning, and public health. In Towards User-Centric Transport in Europe, 149-171. https://doi.org/10.1007/978-3-319-99756-8_11

[3] Diao, M. (2019). Towards sustainable urban transport in Singapore: Policy instruments and mobility trends. Transport Policy, 81: 320-330. https://doi.org/10.1016/j.tranpol.2018.05.005

[4] Bamwesigye, D., Hlavackova, P. (2019). Analysis of sustainable transport for smart cities. Sustainability, 11(7): 2140. https://doi.org/10.3390/SU11072140

[5] Torrisi, V., Garau, C., Ignaccolo, M., Inturri, G. (2020). "Sustainable urban mobility plans": Key concepts and a critical revision on SUMPs guidelines. In International Conference on Computational Science and Its Applications, pp. 613-628. https://doi.org/10.1007/9783-030-58820-5_45

[6] Verlinghieri, E., Schwanen, T. (2020). Transport and mobility justice: Evolving discussions. Journal of Transport Geography, $\quad 87$ : 102798. https://doi.org/10.1016/j.jtrangeo.2020.102798

[7] Lovelace, R., Parkin, J., Cohen, T. (2020). Open access transport models: A leverage point in sustainable transport planning. Transport Policy, 97: 47-54. https://doi.org/10.1016/j.tranpol.2020.06.015

[8] Holz-Rau, C., Scheiner, J. (2019). Land-use and transport planning-A field of complex cause-impact relationships. Thoughts on transport growth, greenhouse gas emissions and the built environment. Transport Policy, $\quad 74: \quad 127-137$. https://doi.org/10.1016/j.tranpol.2018.12.004

[9] Pojani, E., Van Acker, V., Pojani, D. (2018). Cars as a status symbol: Youth attitudes toward sustainable transport in a post-socialist city. Transportation Research Part F: Traffic Psychology and Behaviour, 58: 210-227. https://doi.org/10.1016/j.trf.2018.06.003

[10] Youssef, Z., Alshuwaikhat, H., Reza, I. (2021). Modeling the modal shift towards a more sustainable transport by stated preference in Riyadh, Saudi Arabia. Sustainability, 13(1): 337. https://doi.org/10.3390/su13010337

[11] Sultan, B., Katar, I.M., Al-Atroush, M.E. (2021). Towards sustainable pedestrian mobility in Riyadh city, Saudi Arabia: A case study. Sustainable Cities and Society, 69:

102831. https://doi.org/10.1016/j.scs.2021.102831

[12] Chirieleison, C., Montrone, A., Scrucca, L. (2020). Event sustainability and sustainable transportation: A positive reciprocal influence. Journal of Sustainable Tourism,
28(2):

https://doi.org/10.1080/09669582.2019.1607361

[13] Kumar, A., Anbanandam, R. (2019). Development of social sustainability index for freight transportation system. Journal of Cleaner Production, 210: 77-92. https://doi.org/10.1016/j.jclepro.2018.10.353

[14] Al-Rashid, M.A., Nahiduzzaman, K.M., Ahmed, S., Campisi, T., Akgün, N. (2020). Gender-responsive public transportation in the Dammam metropolitan region, Saudi Arabia. Sustainability, 12(21): 9068. https://doi.org/10.3390/su12219068

[15] Shi, H., You, Z., Feng, Z., Yang, Y. (2019). Numerical simulation and spatial distribution of transportation accessibility in the regions involved in the belt and road initiative. $\quad$ Sustainability, $11(22)$ : 6187. https://doi.org/10.3390/su11226187

[16] Hildén, M., Furman, E., Kaljonen, M. (2004). Views on planning and expectations of SEA: The case of transport planning. Environmental Impact Assessment Review, 24(5):

https://doi.org/10.1016/j.eiar.2004.01.003

[17] Peterson, H. (2021). Built environment accessibility in the eastern province of the Kingdom of Saudi Arabia as seen by persons with disabilities. Journal of Accessibility and Design for All, 11(1): 115-147. https://doi.org/10.17411/jacces.v11i1.294

[18] Tabassum, K. (2020). An intelligent metro tracking system for Riyadh Smart City. International Journal of Information Technology, 12(4): 1103-1109. https://doi.org/10.1007/s41870-020-00435-7

[19] Noland, R.B. (2007). Transport planning and environmental assessment: Implications of induced travel effects. International Journal of Sustainable Transportation, 1(1): 1-28. https://doi.org/10.1080/15568310601095131

[20] Menoret, P. (2019). Learning from Riyadh: Automobility, joyriding, and politics. Comparative Studies of South Asia, Africa and the Middle East, 39(1): 131-142. https://doi.org/10.1215/1089201X-7493843

[21] McGimpsey, P., Morgan, R.K. (2013). The application of strategic environmental assessment in a nonmandatory context: Regional transport planning in New Zealand. Environmental Impact Assessment Review, 43: 56-64. https://doi.org/10.1016/j.eiar.2013.05.007

[22] Abdulrazzaq, L.R., Abdulkareem, M.N., Yazid, M.R.M., Borhan, M.N., Mahdi, M.S. (2020). Traffic congestion: Shift from private car to public transportation. Civil Engineering Journal, 6(8): 1547-1554. https://doi.org/10.28991/cej-2020-03091566

[23] Qoradi, M.D., Al-Harbi, M.S., Aina, Y.A. (2021). Using GIS-based intelligent transportation systems in the enhancement of university campus commuting in a smart city context. Arabian Journal of Geosciences, 14(9): 113. https://doi.org/10.1007/s12517-021-07098-z

[24] Alanazy, A.R.M., Wark, S., Fraser, J., Nagle, A. (2021). Nontransported cases after emergency medical service callout in the rural and urban areas of the riyadh region. Saudi Journal of Medicine \& Medical Sciences, 9(1): 38. https://doi.org/10.4103/sjmms.sjmms_560_20

[25] Banister, D. (2002). Transport Planning (Second.). New York: Spons Press. https://www.routledge.com/TransportPlanning/Banister/p/book/9780415261722.

[26] De Boer, N.E. (1986). Transport Sociology: Social 
Aspects of Transport Planning. Pergamon Press. https://doi.org/10.1016/0191-2607(90)90023-y

[27] Ghadanfar, N.M. (2019). Waiting for the bus: A strategy for approaching the regulation of public transportation in Kuwait. Massachusetts Institute of Technology. https://dspace.mit.edu/handle/1721.1/123955.

[28] Geurs, K.T., Krizek, K.J., Reggiani, A. (Eds.). (2012). Accessibility analysis and transport planning: Challenges for Europe and North America. Edward Elgar Publishing. https://doi.org/10.4337/9781781000113

[29] Alanoud Bandar Alsaud, A.A., Yas, H., Alatawi, A. (2021). A New Decision-Making Approach for Riyadh makes up 50 percent of the non-oil economy of Saudi Arabia. Journal of Contemporary Issues in Business and Government, 27(1): 3376-3392. https://cibgp.com/article_9736.html.

[30] Litman, T., Colman, S.B. (2001). Generated traffic: Implications for transport planning. ITE Journal, 71(4): 38-46.

[31] Dano, U.L., AlQahtany, A.M. (2019). Issues undermining public transport utilization in Dammam city, Saudi Arabia: An expert-based analysis. Journal of Sustainability Science and Management, 14(2): 157-171.

[32] Negev, M., Khreis, H., Rogers, B.C., Shaheen, M., Erell, E. (2020). City design for health and resilience in hot and dry climates. BMJ, 371 . https://doi.org/10.1136/bmj.m3000

[33] Cheng, L., Chen, X., Yang, S., Wu, J., Yang, M. (2019). Structural equation models to analyze activity participation, trip generation, and mode choice of lowincome commuters. Transportation Letters, 11(6): 341349. https://doi.org/10.1080/19427867.2017.1364460

[34] Cohen, J.M., Boniface, S., Watkins, S. (2014). Health implications of transport planning, development and operations. Journal of Transport \& Health, 1(1): 63-72. https://doi.org/10.1016/j.jth.2013.12.004

[35] Ahouzi, K., Assyakh, H., Haddou, L.N., Messaoudi, A. (2020). Territorial competitiveness and smart City: Benchmarking analysis of dubai, abu dhabi, riyadh, cairo, and rabat. The International Archives of Photogrammetry, Remote Sensing and Spatial Information Sciences, 44: 13-20. https://doi.org/10.5194/isprs-archives-XLIV-4-W32020-13-2020

[36] Hoffmann, B. (2019). Air pollution in cities: Urban and transport planning determinants and health in cities. In Integrating Human Health into Urban and Transport Planning, 425-441.

[37] O'Neill, D. (2010). Deciding on driving cessation and transport planning in older drivers with dementia. European Geriatric Medicine, 1(1): 22-25. https://doi.org/10.1016/j.eurger.2010.01.001

[38] Sahito, N., Kalwar, S., Memon, I.A., Mangi, M.Y., Hussain, A. (2020). Examining rapid land-use variation using multicriteria decision analysis (mcda) method. $\begin{array}{lll}\text { International Journal, } & \text { 76(7/1). }\end{array}$ https://doi.org/10.21506/j.ponte.2020.7.7

[39] Messmann, L., Zender, V., Thorenz, A., Tuma, A. (2020). How to quantify social impacts in strategic supply chain optimization: State of the art. Journal of Cleaner Production, 257: 120459. https://doi.org/10.1016/j.jclepro.2020.120459

[40] Almahmoud, E., Doloi, H.K. (2020). Identifying the key factors in construction projects that affect neighbourhood social sustainability.

Facilities.

https://doi.org/10.1108/F-11-2019-0121

[41] Hussain, T., Eskildsen, J., Edgeman, R., Ismail, M., Shoukry, A.M., Gani, S. (2019). Imperatives of sustainable university excellence: A conceptual framework. Sustainability, 11(19): 5242. https://doi.org/10.3390/su11195242

[42] Ali, M., Wazir, R., Imran, K., Ullah, K., Janjua, A.K., Ulasyar, A., Guerrero, J.M. (2021). Techno-economic assessment and sustainability impact of hybrid energy systems in Gilgit-Baltistan, Pakistan. Energy Reports, 7: 2546-2562. https://doi.org/10.1016/j.egyr.2021.04.036

[43] Wang, H.K. (2020). Renewable Energy Management in Emerging Economies: Strategies for growth. Routledge.

[44] Beccastrini, L., Chiacchiari, L., Zappacosta, C. (2020). Economic impact of the third-party assessment: Case study Line 3 Metro Riyadh-Red line. Transportation Research Procedia, 45: 153-160. https://doi.org/10.1016/j.trpro.2020.03.002

[45] Aljoufie, M. (2021). The impact assessment of increasing population density on Jeddah road transportation using spatial-temporal analysis. Sustainability, 13(3): 1455. https://doi.org/10.3390/su13031455

[46] Sedjelmaci, H., Hadji, M., Ansari, N. (2019). Cyber security game for intelligent transportation systems. IEEE Network, 33(4): 216-222. https://doi.org/10.1109/MNET.2018.1800279

[47] Abulibdeh, A.O. (2018). Local transportation and tourism in the MENA region. In Routledge Handbook on Tourism in the Middle East and North Africa, 272-289.

[48] Masoumi, H.E. (2019). A discrete choice analysis of transport mode choice causality and perceived barriers of sustainable mobility in the MENA region. Transport Policy, 79: 37-53. https://doi.org/10.1016/j.tranpol.2019.04.005

[49] Amoatey, P., Sulaiman, H. (2017). Options for greenhouse gas mitigation strategies for road transportation in Oman. American Journal of Climate Change, 6(2): 217. https://doi.org/10.4236/ajcc.2017.62011

[50] Timothy, D.J. (2018). The Middle East and North Africa: A dynamic cultural realm. In Routledge handbook on tourism in the Middle East and North Africa, 24-35.

[51] Aldalbahi, M., Walker, G. (2016). Riyadh transportation history and developing vision. Procedia-Social and Behavioral Sciences, 216: 163-171. https://doi.org/10.1016/j.sbspro.2015.12.024

[52] Almannaa, M.H., Alsahhaf, F.A., Ashqar, H.I., Elhenawy, M., Masoud, M., Rakotonirainy, A. (2021). Perception analysis of E-scooter riders and non-riders in Riyadh, Saudi Arabia: Survey outputs. Sustainability, 13(2): 863. https://doi.org/10.3390/su13020863

[53] Alanazi, A. (2020). Smartphone apps for transportation by people with intellectual disabilities: Are they really helpful in improving their mobility? Disability and Rehabilitation: Assistive Technology, 1-7. https://doi.org/10.1080/17483107.2020.1820085

[54] Almaatouq, A. (2016). Complex systems and a computational social science perspective on the labor market. arXiv preprint arXiv:1606.08562.

[55] Al Hosain, N., Alhussaini, A. (2021). Evaluating Access to Riyadh's Planned Public Transport System Using Geospatial Analysis (No. ks--2021-dp10).

[56] Alkahtani, K.F., Abdel-Aty, M., Lee, J. (2019). A zonal 
level safety investigation of pedestrian crashes in Riyadh, Saudi Arabia. International Journal of Sustainable Transportation, 13(4): 255-267. https://doi.org/10.1080/15568318.2018.1463417

[57] Alkhamis, K.N., Abdulkader, R.S. (2020). Assessment of unintentional childhood injuries and associated factors in the pediatric clinics of a tertiary care hospital in Riyadh, Saudi Arabia. Journal of Family \& Community Medicine, 27(3): 168. https://doi.org/10.4103/jfcm.JFCM_75_20

[58] Salman, A., Al-Tayib, M., Hag-Elsafi, S., Zaidi, F.K., Al-Duwarij, N. (2021). Spatiotemporal assessment of air quality and heat island effect due to industrial activities and urbanization in Southern Riyadh, Saudi Arabia. Applied Sciences, 11(5): 2107. https://doi.org/10.3390/app11052107

[59] Nassar, U.A. (2021). Urban acupuncture in large cities: filtering framework to select sensitive urban spots in riyadh for effective urban renewal. Journal of Contemporary Urban Affairs, 5(1): 1-18. https://doi.org/10.25034/ijcua.2021.v5n1-1

[60] Lee, S.M., Al-Mansour, A.I. (2019). A traffic analysis and redesign of transportation facilities: A case of imam abdullah bin saud road and khaled bin Al walid street interchange. International Journal of Transportation Engineering and Traffic System, 5(1): 1-11.

[61] Palmer Peterson, H., Al Kassim, Z. (2020). A case study on perceptions of public transportation in the eastern province of Saudi Arabia. Transport Problems, 15. https://doi.org/10.21307/TP-2020-015

[62] Preston, J. (2021). The total social cost (TSC) of public transport modes. In Handbook of Public Transport Research. Edward Elgar Publishing.

[63] Alhumoud, S. (2019). Twitter analysis for intelligent transportation. The Computer Journal, 62(11): 15471556. https://doi.org/10.1093/comjnl/bxy129

[64] Abdelsattar, A., Al Nadhairi, R., Hassan, A.N. (2021). Space-based monitoring of $\mathrm{NO}_{2}$ levels during COVID19 lockdown in Cairo, Egypt and Riyadh, Saudi Arabia. The Egyptian Journal of Remote Sensing and Space Science. https://doi.org/10.1016/j.ejrs.2021.03.004

[65] Alabed, A.M., Abdulmughni, A.M., Alzamil, W. (2021). The characteristics of livable streets: A study of physical aspects of two streets in Riyadh. Journal of Urban
Research, 39(1): 43-58. https://doi.org/10.21608/jur.2020.33668.1007

[66] Yousif, G.M.A. (2019). The impact of transportation infrastructure on economic growth: Empirical evidence from Saudi Arabia. Journal of Economics, Management and Trade, 1-13. https://doi.org/10.9734/jemt/2019/v23i430138

[67] Sulaiman, F.B., Almahmood, M. (2021). Following the process: unfolding how form-based code - as a travelling concept - has been adapted within the social, cultural, and architectural context of Riyadh. URBAN DESIGN International, 1-21. https://doi.org/10.1057/s41289-02100163-9

[68] Aina, Y.A., Wafer, A., Ahmed, F., Alshuwaikhat, H.M. (2019). Top-down sustainable urban development? Urban governance transformation in Saudi Arabia. Cities, 90: 272-281. https://doi.org/10.1016/j.cities.2019.03.003

[69] Williams, S., Qiu, W., Al-awwad, Z., Alfayez, A. (2019). Commuting for women in Saudi Arabia: Metro to driving-Options to support women employment. Journal of Transport Geography, 77: 126-138. https://doi.org/10.1016/j.jtrangeo.2019.05.002

[70] Radwan, F., Alazba, A.A., Mossad, A. (2020). Analyzing urban watersheds morphometric in arid and semiarid regions using the complementarity of RST and GIS. Arabian Journal of Geosciences, 13(23): 1-21. https://doi.org/10.1007/s12517-020-06161-5

[71] Alotaibi, M.D., Alharbi, B.H., Al-Shamsi, M.A., et al. (2020). Assessing the response of five tree species to air pollution in Riyadh City, Saudi Arabia, for potential green belt application. Environmental Science and Pollution Research, 27: 29156-29170. https://doi.org/10.1007/s11356-020-09226-w

[72] Chavhan, S., Gupta, D., Garg, S., Khanna, A., Choi, B.J., Hossain, M.S. (2020). Privacy and security management in intelligent transportation system. IEEE Access, 8: 148677-148688. https://doi.org/10.1109/ACCESS.2020.3015096

[73] Al-Khanbashi, M. (2020). The transformation of ArRiyadh's landscape from constructivism perspective. In Landschaft als Prozess, 689-713. https://doi.org/10.1007/978-3-658-30934-3_32 